\title{
Secondary School Writing Errors at White Nile State Sudan: A Case Study of Assalaya Locality
}

\author{
Dr. Elrayah Eltahir Adam Khatir \\ Assistant Professor of English, Faculty of Education, University of Bakht-er- Ruda, Sudan- Gassim University KSA
}

\begin{abstract}
This study has taken place at Assalaya secondary school in Sudan to discover the problems of English language writing errors. It is clear that learners make mistakes in the process of foreign language writing. However, what language teachers and experts question is why do students make the same mistakes, even when such mistakes repeatedly explained to them? Yet not all mistakes are the same. Some are easy to be reformed, and others fossilized. Therefore, it is the researcher's intention to subject all these problems into focus of evaluation to point out the types of writing errors to provide evidence of how language is learned and what strategies or procedures the learners are employing in the discovery of this language writing errors. The researcher used the descriptive analytical approach to evaluate the phenomena of the writing errors to find solutions, which must be beneficial for learners as well as expert and teachers. The result shows that students cause lexical errors, verb choice, punctuation, spelling errors and others. Then the researcher recommends more comprehensive study on the English writings of the students have to be conducted to solve this problem.
\end{abstract}

Keywords: ssw errors

\section{Introduction}

Error analysis is a branch of applied linguistics, emerged in the sixties to demonstrate that learner errors were not only because of the learner's native language but also they reflected some universal learning strategies, as a reaction to contrastive analysis theory, which considered language transfer as the basic process of second language learning as what behaviorist theory suggested. Error analysis, on the other hand, deals with the learners "e performance in terms of the cognitive processes they make use of in recognizing or coding the input they receive from the target language. Therefore, a primary focus of error analysis is on the evidence that learnerse errors provide with an understanding of the underlying process of second language acquisition. At this point, Keshavars (1997) suggests that the field of error analysis can be divided into two branches: (i) theoretical, and (ii) applied. Theoretical analysis of errors primarily concerns the process and strategies of language learning and its similarities with first language acquisition. In other words, it tries to investigate what is going on in the minds of language learners. Secondly, it tries to decode the strategies of learners such as overgeneralization and simplification, and thirdly, to go to a conclusion that regards the universals of language learning process whether there is an internal syllabus for learning a second language.

Applied error analysis, on the other hand, concerns organizing remedial courses, and devising appropriate materials and teaching strategies based on the findings of theoretical error analysis.

For years, there have been many studies on the process of first language acquisition and second language learning. Findings about first language acquisition have been adapted to foreign language learning and it has been concluded that the process works in a similar way even for this paper after discovering the problems of errors.

\section{The Statement of Research}

Error analysis enables teachers to find out the sources of errors and take pedagogical precautions towards them. Thus, the analysis of learner language has become an essential need to overcome some questions and propose solutions regarding different aspects. This study concerns the error analysis and its contribution to English language writing at Assalaya locality secondary schools in Sudan.

\section{The Objectives of the Study}

This study aimed to analyze the English writings errors of Assalaya locality secondary schools in Sudan. to identify, describe the students" writing errors committed by the students and investigate their causes more specifically to:

- Find out the errors that faces the learners at Assalaya secondary school.

- Correct the language errors at secondary school.

- Help the students at basic schools to reduce their errors.

- Display the problems of the error in English usage to the teachers and expert in the field of language.

\section{Hypothesis of the Study}

This study has the following hypotheses:

- Students cause errors due to the lack of training.

- The students cause different types of errors due to the irresponsible learning.

- The interference of the first language affects the using of foreign language.

- The overgeneralization causes errors in using foreign language.

\section{Questions of the Research}

This study tries to answer these questions:

a) Why pupils make errors when they use foreign language?

b) How pupils overcome these writing errors?

\section{Tools population the Study}

The population of the study consists of basic secondary school at Assalaya locality in Sudan .40 students compositions and essay writing are taken randomly to represent the study. 


\section{International Journal of Science and Research (IJSR) \\ ISSN (Online): 2319-7064 \\ Index Copernicus Value (2013): 6.14 | Impact Factor (2014): 5.611}

\section{Significance of the Study}

This research is going to be beneficent for the teachers and the learners of English language. It provides relief to language teachers to find a more realistic attitude towards errors. For the students, they are given the true picture of what they need to learn, focusing on how to overcome the linguistic difficulties they manifest.

\section{Literature Review}

\subsection{Language Learning and Habit Formation}

In the fifties language learning was considered to be a matter of habit formation. The structural linguists thought that language could not be compared as every language has to be described in terms of its own structure. This coupled with the viewpoint of habit formation theory gave rise to what is known as "Contrastive analysis ${ }^{e e}$. According to this when a child first acquires a language its peculiar patterns are stamped in the mind of the child. Hence when he starts to learn a second language those items which are the same as that of his first language causes him no difficulty. Those which are more or less similar also do not pose much of a problem. But the items which are completely different from his mother tongue give him a lot of trouble.

So if we compare the phonology, lexis, syntax and semantics of his first language with parallel items in his second language we would be able to predict the difficulties he might face with. As far back as1945 C. C. Fries remarked that effective materials could be produced if they are based on a scientific description of both the mother tongue and the target language of the learner. This was later elaborated by Lado in 1957. But no doubts have been raised about the use of contrastive linguistics to language teaching.

According to Pit Corder (1978) it is paradoxical to say that language cannot be compared but such a comparison is necessary to produce effective materials. He gives three valid reasons why itis not as useful as it claims to be.

The following are the three reasons:

1) Not all difficulties and errors can be traced back to the influence of the mother tongue. (This is supported by Richards(1981), Dulay and Burt (1973), Duskova (1969)).

2) What contrastive analysis predicted as a difficulty did not always in practice turn out to be so (This is supported by Nickel).

3) Adequate comparison of two languages can only have doubtfulvalidity because of theoretical problems (Hamp (1969). VanBuren (1974), Kreszowski (1974)).

Wardhau (1970) makes a clear distinction between the strong and weak hypothesis of contrastive linguistics.

1) The strong hypothesis states that the difficulties of the learner can be predicted by a systematic contrastive analysis and teaching material can then be devised to meet those difficulties.

2) The weak hypothesis claims no more than an explanatory role where when difficulties are evident from the errors made by the learner comparison between the mother tongue and the target language of the learner may help to explain them.

Since 1968 there has been a gradual change and research projects in the area of contrastive analysis have broadened their scope in two directions. These two directions are as follows:

1) Towards more theoretical objectives in language typology and the search for universals.

2) Towards psycholinguistic orientation concerned with the explanation of second language acquisition.

This new development has been called „Contact analysise Nemser and Slama-cazacu (1970-71) suggest that the task of contact analysis is to "explain and predict language learner behaviours with the concrete aim of developing a more scientific approach to the process of foreign language teaching." Here it merges significantly with error analysis which is based on the theory of language learning as a process of cognitive development.

\subsection{Language Learning and Cognitive Development}

According to the cognitive development theory, the human brain is programmed to learn a language. It is programmed in such a way that it can learn any language to which it is exposed. From the amount of exposure received children collect some data process it and try to build up a grammar for themselves. They do not possess a set of dispositions to respond mechanically to external stimuli. Instead they try to internalize certain rules and try to respond to the external stimuli to the best of their ability.

As cognitive development came to be associated with language learning it was thought learners need not unlearn their first language to learn a second language. Instead they are said to use certain strategies to acquire a set of cognitive structures from the data they receive. These strategies could be similar to the ones used by them when they acquired their first language. As it is normally observed that errors it is considered natural for children acquiring a first language commit a lot of second language learners also to commit a number of errors.

The errors of the first language learners reveal the strategies they are using to learn the language. Similarly the errors of the second language learners also give an indication as to what strategies they are using to learn the language. These speculations led to the study of errors as the most significant data on which a reconstruction of the learners ${ }^{e c}$ knowledge of the target language could be made.

Pit Corder (1967) says that the processes of first and second language acquisition are fundamentally the same. If the utterances of the first and second language learners differed it could be accounted for by differences in (1) maturational development (2) motivation for learning and (3) the circumstances of learning. In spite of these differences both first and second language learners build up their own grammar and gradually proceed towards the grammar of the language they are learning. 


\section{International Journal of Science and Research (IJSR) \\ ISSN (Online): 2319-7064 \\ Index Copernicus Value (2013): 6.14 | Impact Factor (2014): 5.611}

This system which the learners build up for themselves has been given various names but the most widely used terminology is that suggested by Selinker (1974). He calls this Interlanguage to emphasize the structurally intermediate status of the learner's language system between his mother tongue and his target language. A detailed study of this Interlanguage could help us to understand the learners ${ }^{\text {ee }}$ problems better and try to provide timely help to our learners so that they achieve competence in the language they are trying to learn.

Whenever a language is learnt or acquired one is faced with the problem of errors. Errors are an inevitable feature of learning. They are not problems to be overcome or evils to be eradicated. They in fact are part of learning and reveal the strategies that learners use to learn a language. They provide valuable insight into the language learning process.

They help the teachers infer how much the learners have learnt. They also give an indication as to whether they are ready to learnwhat the teacher wants to teach them next. Thus a lack of fit between the learner's needs and the items taught could be avoided.

By analyzing the errors one could build up a picture of the features of language which cause learning problems. Once the problems are understood in the right perspective remedial measures could be planned. An important part of the teachers ${ }^{\text {ee }}$ job is to undertake a systematic analysis of learners ${ }^{c e}$ errors.

\subsection{Historical Background to the field of errors analysis}

Until late sixteen, the prominent theory regarding the issue of second language learning was behavioristic which suggested that the learning was largely a question of acquiring a set of new language habits. Errors were considered as being the results of the persistence existing mother tongue habits in the new language consequently. This idea made the researchers of applied linguistics devote their largely to the comparison of the native and target language in order to make predictions and explanation about errors. However errors that were not explained in this way were underestimated. All errors whatever their origins were dealt with the same technique of further drilling and exercise.

\footnotetext{
Mistake

Identify an errors goes beyond explaining what an error is. However, as linguists pay attention to the distinction between an error and a mistake, it is necessary to go over the definition of the two different phenomena. According to dictionary of language teaching and applied linguistics (1992) a learner makes a mistake when writing or speaking because of lack of attention, fatigue carelessness or some other aspects of performance. Mistakes can be self. corrected when attention is called an error is the use of linguistic item in a way that a fluent or native speaker of the language regards it as showing faulty of incomplete learning. To distinguish between an error and mistake Ellis (1997) suggests two ways the first one is check the consistency of learner's performance. If he sometimes uses the correct form and sometimes the wrong one, it is a
}

mistake if always uses it in correctly, it is an error. The second way is to ask learner to try to correct his own deviant utterance. Where he is unable to the derivation are errors, where he is successful, they are mistakes.

\section{Approaches to Errors:}

As Jean D'Souza (1977) points out. in the fifties and early sixties errors were looked upon as evils which had to be eradicated. It was believed that if the teacher taught well and drilled the patterns of the new language efficiently there was no reason for the learners to make any errors at all.

As more and more studies have been undertaken it has been proved that learners ${ }^{\text {ee }}$ errors show evidence of a system. The learners try to evolve a language system of their own on the basis of the exposure they receive. They constantly try to bring their system in line with the system of the language they are exposed to. In so doing they formulate and discard hypotheses. According to Strevens (1969) if a regular pattern of errors could be observed and the learners were seen to progress through this pattern it was a sign of achievement in learning. With this change in attitude the emphasis of error analysis has also changed.

As errors began to be considered as specific indications of the learning process the emphasis of error analysis changed from the ,product ${ }^{\text {ee }}$ to the ,process ${ }^{\text {ee }}$ behind it. That is, in the early sixties the main concentration was on the errors themselves. Later the emphasis shifted to the process or systems behind the errors.

It was realized that the learners evolve a system for themselves which is much simpler than the system of language being learnt by them. They seemed to ignore certain redundancies revise some rules if necessary and simplify their learning task. But they were also found to change this system as per the increasing exposure to the language they were learning. Hence errors can be looked upon as a developmental phenomena. providing evidence regarding the rules and categories used by the learners at a particular time.

The process is given importance because it throws light on how the language is learnt. The study of errors also helps us to infer what the nature of learners ${ }^{\text {ee }}$ knowledge is at that point of time in their learning career and what more has to be learnt. As Corder (1973) says, "By describing and classifying his errors in linguistic terms we build up a picture of the features of language which are causing him learning problems".

This would in turn help us to produce materials which can help the learners when and where needed. At the same time it would warnus not to interfere too much in their learning process. For this a systematic analysis of the learners ${ }^{\text {ee }}$ errors should be undertaken.

\section{Stages of Error Analysis}

Error Analysis is carried out in three successive stages as mentioned by Pit Corder (1973) These are (1) Recognition (2)Description and (3) Explanation. There are a number of problems which one has to face in each of these stages. A thorough understanding of these problems along with 


\section{International Journal of Science and Research (IJSR) ISSN (Online): 2319-7064 \\ Index Copernicus Value (2013): 6.14 | Impact Factor (2014): 5.611}

possible measures to overcome them is necessary for a proper analysis of the errors.

\section{Recognition of Errors}

To recognize an error one should first of all know what is meant by the term ,error ${ }^{e}$. Pit Corder uses the term "Erroneous" to mean those utterances which are either superficially deviant or inappropriate in terms of the target language grammar. He distinguishes between mistakes, lapses and errors. They correspond to what he calls Presystematic, Post-systematic and Systematic errors.

1) Pre-systematic errors are those committed by the learners while he or she is trying to come to grips with a new point

2) Post-systematic errors occur when one temporarily forgets a

3) point that has been previously understood

Systematic errors are those which occur when the learner has formed inaccurate hypothesis about the target language (i.e. the language that he is learning).

Even native speakers utterances are full of slips of the tongue and lapses. These are supposed to increase under conditions of stress, indecision and fatigue. If this is the case with native speakers second language learners are sure to encounter these problems perhaps to a greater degree. In such cases the teacher may not always be able to distinguish such lapses from errors.

As Pit Corder points out, "Recognition of error is thus crucially dependent upon correct interpretation of the learnerse intentions". He talks about two types of utterances:

The two types of utterances mentioned by Pit Corder are as follows:

1) Overtly erroneous -Superficially deviant

2) Covertly erroneous - Superficially well formed but not meaning what the learner intended to mean

To arrive at a knowledge of what the learner intended to say one can ask the learner to explain in his mother tongue what he wanted to say. An interpretation based on this is called, authoritative interpretation ${ }^{\text {ee }}$. Then the utterances are reconstructed keeping in mind what the native speaker would have said to convey that message in that context. This is called an, authoritative reconstruction ${ }^{\text {ee }}$

In cases where one does not have access to the learner what is called a ,plausible interpretation ${ }^{\text {ee }}$ and a ,plausible reconstruction ${ }^{\text {ee }}$ could be made. This is done by studying the surface structure of the text-sentence in conjunction with the information derived from its context. Then the utterances are reconstructed to convey what the learner could possibly have intended to mean. To identify errors the original utterances are compared with their plausible or authoritative reconstructions. Once the recognition has taken place description could begin.

\section{Description of Errors:}

In this step one tries to show the learners how they have failed to realize the intended message. There are problems which prevent proper description as the researcher needs an extremely good insight into the learner's mind. Mc.
Donough (1981) remarks that it should not be supposed that all learners take the same route to the same error "Nor should it be assumed that one learner may not at different times produce the same error for different reasons".

But Pit Corder feels this is irrelevant for "our object in error analysis is to explain errors linguistically and psychologically in order to help the learner to learn". He suggests that we should look for errors that occur repeatedly so that we can observe the rule that the learner may be using and try to describe it. This way only systematic errors are taken into consideration. This is a difficult task because individual learners may be highly inconsistent in their errors. Corder agrees that inconsistency is more characteristic of errors than systematicity. Once the errors are described properly explanation of errors can begin.

\section{Explanation of Errors:}

Explanation is still largely speculative because of our limited knowledge of the psychological and neurological process involved in language learning. The same error could be looked at from various points of view. For example. a learneres mother tongue has only one way of referring to future time while the target language has three ways of referring to the same. Here the learner has problems and commits errors. In this case it is difficult to decide whether the error was caused by mother tongue interference or because of the confusion of the rules of the target language. According to David Lott (1983) mother tongue does not actually interfere though it does not give any guide to the learner. Nickel(1971) takes a wider view and considers the above example as an interference error. But he says in such cases we should distinguish between direct and indirect interference. Dulay and Burt (1974) define interference as the automatic transfer of the structure of the target language due to habit. Pit Corder (1973) refers to three types of errors. These are: (1)transfer errors. (2) Analogical errors and (3) teaching-induced errors. Selinker (1974) suggests five processes which are more or less similar to that suggested by Pit Corder but in addition includes strategies of second language learning and strategies of second language communication to explain the nature of errors. Once we have decided to give an explanation from a particular point of view we can start classifying the errors. But there are a number of problems in classification too.

\section{Classification of Errors:}

The main problem one faces in the area of classification is that one error can be classified in a number of ways. The following example dealt with by A.K.Sinha (1977) makes clear some of the problems one has to face while analyzing syntactic errors. The example is as under:

a) The plane reached Detroit. There it stopped for half an hour.

b) The plane reached Detroit and stopped there for half an hour.

c) The plane reached Detroit. There stopped for half an hour.

In (C) according to the structuralist the sentence is erroneous because the subject is missing. The proper use of it is made in (a). According to a transformationalist a ,conjoined co reference subject deletion rule ${ }^{e c}$ is used in the wrong place in (c). It has been rightly used in (b). Application of a Hindi-

\section{Volume 4 Issue 11, November 2015}




\section{International Journal of Science and Research (IJSR) \\ ISSN (Online): 2319-7064 \\ Index Copernicus Value (2013): 6.14 | Impact Factor (2014): 5.611}

knowing speaker of English would say it is the ,the co reference subject deletion rule ${ }^{e e}$ in Hindi which permits intersentential deletion of a co referential subject. A number of examples of this type have been cited by many to make the point that differences of opinion exist with regard to classification of errors. But once the choice is made as to which type of classification one wants to employ one can deal with it efficiently. Whatever the approach may be one thing stands out clear. Learners employ certain strategies to simplify their learning task. This is true whether they are learning their mother tongue or a second language. This fact is clearly seen when one studies their syntactic errors. Hence the study of learners ${ }^{\text {ec }}$ errors could help us in two ways. Firstly we can understand the processes of language acquisition and secondly we can prepare materials which are suited to the needs of the learner. So far the discussion has focused on how Error Analysis helps us gain a better understanding of the processes of language learning. Looking at it from a different point of view it can be seen how various studies which have been carried out with a view to finding out how language is acquired by children have changed our attitude and approach towards errors.

\section{Description of Errors:}

A number of different categories for describing errors have been identified firstly, Corder (1973) classifies errors of the difference between the learners utterance and the reconstructed version. In this way, errors fall into four categories

\section{Omission:}

Morphological mission / Astrange strange thig happened to me yesterday.

Syntatical omission / must say also the name?

\section{Addition:}

In morphology / the book is here.

In syntax / the London

In lexicon /I stayed there during five years ago.

\section{Selection}

In morphology - my friend is oldest than me.

In syntax -I want that he comes here.

\section{Ordering}

In pronunciation fignisicant for significant brulal for plural?

In morphology - get upping for ' getting up '

In syntax - he is adear to my friend

In lexcon - key ear for 'car key'

An error may vary in magnitude. It can include phoneme, a morpheme, a word, a sentence or even a paragraph. Due to this fact, errors may be also viewed as being either global or local (cited in Brown, 2 000) global errors hinder communication

\section{Sources of errors}

There many descriptions for different kinds of errors, it is inevitable to move further and ask for the sources of errors. It has been indicated in the first part of the study that errors were assumed as being the only result of interference of the first language habits to the learning of second language.

However, with the field of error analysis, it has been understood that the nature of errors implicate the existence of other reasons foe errors can be categorized with in two domains (i)interlingual transfer and (ii)intralingual transfer. Interlingual transfer is significant source for language learners. Intralingual transfer the interferences from the students own language is not only reason for committing errors.

\section{Pedagogical implications of error analysis}

The studies regarding errors are carried out in order to (i) identify strategies which learners use in language teaching (ii) identify the cause of learners errors, (iii) obtain information on common difficulties in language learning as an aid to teaching or in development in teaching materials. students errors have always been of interest and significance to teachers, syllabus designers and test developers.

\section{Implications for foreign language teachers}

Teacher can benefit from the findings error analysis in many ways, errors tell the teacher how far towards the goal the learner has progressed and what remains for him to learn (corder.1987) following the students progress, the teacher able to carry on his studies in accordance with what learners needs to know. Errors are means of feedback for the teacher strategy to chance or reconstruct.

\section{Implications for syllabus designers}

Syllabus design of an English teaching course is a very important component of teaching-learning process. There are many factors to be considered to decide on what to teach to what level and age group .at this point; errors are significant data for syllabus designers as they show what items are important to be included or which items needs to be recycled in the syllabus.

\section{Error correction and error analysis}

(At the beginning of the study commit errors) some other questions rise; how should teachers correct students? What kind of feedback should they give? Dose each error need to be treated? error analysis has an important role in finding the answers to these questions. In general the teachers .job is to point out when something has gone wrong and see whether the student can correct himself, to find out if what the student say or write is just a mistake, or it is global or local.

\section{Methodology}

This study focused on the English writings of the students of Assalaya secondary school white Nile state in Sudan who are resuming their studies to sit for the Sudan secondary school certificate. The respondents were second year students, who had already taken English as separate subject in which writing composition is given in one day a week. The students' first language is Arabic language and they study English as foreign language.

The students were asked to write free composition or short essay of not less than 400 words about any topic of their own. They were given enough time to write. The process of

\section{Volume 4 Issue 11, November 2015}




\section{International Journal of Science and Research (IJSR) \\ ISSN (Online): 2319-7064 \\ Index Copernicus Value (2013): 6.14 | Impact Factor (2014): 5.611}

writing was followed. The students started with an outline, then a first draft and a final draft.

In a random sampling technique, 40 compositions and essays were taken to represent the study and they were subjected to error analysis

Students errors found in their writings were analyzed and categorized according to the Taxonomy of Errors patterned after the model of Darus and Ching (2009), which categorizes errors as to: a) grammatical (prepositions, articles, reported speech, singular/plural, adjectives, relative clauses, infinitives, verbs and tenses, and possessive case); b) syntactic (coordination and conjunctions, sentence structure, nouns and pronouns, and word order); c) lexical (word choice); d) semantic (literal translation); and e) substance/mechanics (punctuation, capitalization and spelling). Describing the prevailing linguistic errors was further made.

Focused group discussion (FGD) was also carried out to selected students for the perceptive understanding about the errors they committed, particularly for possible causes of these errors. The study used frequency count $(f)$, percentage $(\%)$ and rank (r) as statistical tools to analyse the collected data.

\section{Results and Discussion}

This section presents discussion of the results and findings of the study. Specifically, it presents and describes the common linguistic errors committed by the students. Furthermore, it investigates possible causes of these errors and discusses implications to language learning and teaching.

Table 1 shows the analysis of data that deals with the common linguistic errors committed by the students in their written compositions, including the situation of error gravity which establishes the hierarchy of errors. Evidently, there are a total number of 394 linguistic errors identified and tallied.

Table 1: Result of error analysis in the English writings of the students

\begin{tabular}{|l|c|c|c|}
\hline \multicolumn{1}{|c|}{ Linguistic Errors } & $\begin{array}{c}\text { Count of } \\
\text { error }(f)\end{array}$ & $\begin{array}{c}\text { Percentage } \\
(\%)\end{array}$ & $\begin{array}{c}\text { Hierarchy } \\
(r)\end{array}$ \\
\hline A. Grammatical Errors & & & \\
\hline Verb Tenses & 76 & 19.29 & 1 \\
\hline Prepositions & 62 & 6.6 & 6 \\
\hline Articles & 24 & 6.09 & 7 \\
\hline Infinitives & 6 & 1.52 & 12 \\
\hline Reported Speech & 6 & 1.52 & 12 \\
\hline Singular/Plural & 4 & 1.01 & 16 \\
\hline Adjectives & 4 & 1.01 & 16 \\
\hline Relative Clauses & 4 & 1.01 & 16 \\
\hline Possessive Case & 4 & 1.01 & 16 \\
\hline Total & 145 & 39.02 & \\
\hline
\end{tabular}

\begin{tabular}{|c|c|c|c|}
\hline Linguistic Errors & $\begin{array}{c}\text { Count of } \\
\text { error }(f)\end{array}$ & $\begin{array}{c}\text { Percentage } \\
(\%)\end{array}$ & $\begin{array}{c}\text { Hierarchy } \\
(r)\end{array}$ \\
\hline A. Grammatical Errors & & & \\
\hline Verb Tenses & 76 & 19.29 & 1 \\
\hline Prepositions & 62 & 6.6 & 6 \\
\hline Articles & 24 & 6.09 & 7 \\
\hline Infinitives & 6 & 1.52 & 12 \\
\hline Reported Speech & 6 & 1.52 & 12 \\
\hline Singular/Plural & 4 & 1.01 & 16 \\
\hline Adjectives & 4 & 1.01 & 16 \\
\hline Relative Clauses & 4 & 1.01 & 16 \\
\hline Possessive Case & 4 & 1.01 & 16 \\
\hline Total & 145 & 39.02 & \\
\hline
\end{tabular}

\begin{tabular}{|c|c|c|c|}
\hline B. Syntactic Errors & & & \\
\hline Sentence Structure & 66 & 16.75 & 2.5 \\
\hline Coordination/Conjunction & 10 & 2.54 & 9.5 \\
\hline Nouns and Pronouns & 10 & 2.54 & 9.5 \\
\hline Word Order & 4 & 1.01 & 16 \\
\hline Total & 90 & 22.84 & \\
\hline
\end{tabular}

\begin{tabular}{|c|c|c|c|}
\hline C. Lexical Errors & & & \\
\hline Word Choice & 36 & 9.14 & 4 \\
\hline Total & 36 & 9.14 & \\
\hline
\end{tabular}

\begin{tabular}{|c|c|c|c|}
\hline D. Semantic Errors & & & \\
\hline Literal Translation & 12 & 3.05 & 8 \\
\hline Total & 12 & 3.05 & \\
\hline
\end{tabular}

\begin{tabular}{|c|c|c|c|}
\hline E. Mechanics/Substance & & & \\
\hline Punctuations & 66 & 16.75 & 2.5 \\
\hline Spelling & 30 & 7.61 & 5 \\
\hline Capitalization & 6 & 1.52 & 12 \\
\hline Total & 102 & 25.86 & \\
\hline Total & 394 & 100.00 & \\
\hline
\end{tabular}

It is clear that errors in verb tenses are the most common linguistic errors of the students with a total of $76(19.29 \%)$ occurrences, followed by error in sentence structure (66 or $16.75 \%$ ), punctuations (66 or $16.75 \%$ ), word choice (36 or $9.14 \%$ ), spelling (30 or $(7.61 \%)$, prepositions (26 or $6.60 \%$ ) and articles ( 24 or $6.09 \%$ ).

Among all indicated linguistic errors, errors in verb tenses are the most common or prevailing errors of the students in their English writings, with $76(19.29 \%)$ total number of occurrences. It was clearly observed from the studentse compositions that they are not consistent in the use of verb tenses. The fact that the compositions are told in the past form of the verbs, they are not cautious of the correct verb tenses to be used. Likewise, they are not aware that verbs also indicate time of occurrence. For example:

We all swum at the beach yesterday.

The cat drunk all the milk.

The shirt shrunk after a week.

Here the error is in the past participle forms. The past participle forms are used to make perfect tense forms. They are always preceded by a form of have (has, have or had). The past simple is the second form of the verb. Note that this tense form is not preceded by an auxiliary verb. Some verbs have identical simple past and past participle forms. Students should familiarize themselves with the different forms of common verbs. 


\section{International Journal of Science and Research (IJSR) \\ ISSN (Online): 2319-7064}

Index Copernicus Value (2013): 6.14 | Impact Factor (2014): 5.611

So they must be:

We all swam at the beach yesterday.

The cat drank all the milk.

The shirt shrank after a week.

So the students are not conscious of the right verb tenses appropriate for the time of occurrence. Students ${ }^{\text {ee }}$ carelessness and ignorance on the application of rules on verb forms, particularly tenses, are the primary causes of these errors. The result supports the claim of Sukasame, Kantho, and Narrot (2013) that learners of English as a foreign language (EFL) and English as a second language (ESL) have so much difficulty on tense selection. According to them, though they can use all the tenses comfortably, in some situations they are not confident enough to select the correct tense for consistency.

Such claim is also true to the study of Lim (1990) revealing that English language learners know the rules of tense but when they are supposed to apply the rules, they just jumble it. She added that learners think in their L1 then translate it into English. At the time of translating into English, they feel confused in which tense form they can use specially in present and past tense like whether the sentences should be in present or past form. Limited knowledge of form of verbs and lacking in how to use auxiliary verbs make errors in tense.

Relevant to the foregoing issue, Lennon (1987) identified a total of 2455 errors in the English compositions of 12th grade Korean EFL learners. Findings showed that errors in be verbs and auxiliaries were most common, followed by errors in prepositions and that intralingual errors arose more than transfer errors.

Errors in sentence structure (66 or 16.75\%) appear to be the next most common errors committed by the students. It was observed from the written work of the students that they could hardly identify the difference of a sentence and a fragment. Moreover, the studentse sentences are run-on, making it very confusing for readers. In addition, some of the students are even fond of circumlocution. They could not express their ideas in a direct and clear fashion, leading the sentences to vague and dangling ones. For example:

\section{This is a sixth-Months course.}

It sound ok but it is not ok. So the mistake here is (s) ending when I use such expression (six-months) it became an adjective for the noun course so we should say this is ( a six -Month) this is a million dollar contract and so on.

These forms of errors are attributed to studentse poor knowledge on structure of English which leads to incomprehensible statements in their writings. Hence, the need for enrichment activities on the said problem area is important. Importantly, their language teachers need to encourage and expose them to various reading materials to improve their language skills, particularly on the syntactic aspect of English.
Tied with errors on sentence structure, errors in punctuations (66 or $16.75 \%$ ) are also indicated as most common linguistic errors committed by the students. Through the analysis made, it was observed that most of the students omit comma before a relative clause. They use comma incorrectly. Likewise, the use of ellipsis was over used, when in fact the sentence can be marked with a single period only (i.e. I thought it was the end...). For example:

She wished she had some ice cream and because it was raining, she asked her roommate to drive her to the store, but she refused.

Divide the comma-spliced sentence into smaller sentences, replacing the erroneous comma with appropriate ending punctuation.

So the sentence will be:

She wished she had some ice cream. Because it was raining, she asked her roommate to drive her to the store, but she refused.

The said prevailing linguistic phenomena, according to Corder (1974), are referred to as addition of some unnecessary element and omission of some required element, which are classifications of errors in terms of the difference between the learner's utterance and the reconstructed version. The students confessed that they have poor knowledge on the use of punctuations, making it difficult for them to use punctuations correctly and appropriately.

Fourth in rank are errors in word choice, with $36(9.14 \%)$ total number of occurrences. It was observed that the students have difficulty in choosing correct or appropriate words to express their ideas clearly. Some messages are totally obscure due to incorrect word usage. For example:

\section{What's the different?}

Different is an adjective what to use here is the noun and the noun is difference.

\section{I met John two years before.}

If you use the word before then you have to say before something .before I graduated, before I got married so the proper word is ago.

\section{Today this morning I wake up late.}

It should be this morning

Such finding only indicates that the students have limited vocabulary. They are not aware of increasing vocabulary. They admitted that they seldom read books, newspapers, articles, etc. Most of the male students revealed that they are engrossed to surfing the net and playing computer games They have poor attitude towards reading. They are not wellmotivated to read. Generally, most of the students admitted that they simply memorize synonyms and antonyms to improve their vocabulary.

The computed result reaffirms the study of Huang (2001) who presented an analysis of 34 Taiwanese English majors writing errors based on a web-based writing program. His 


\section{International Journal of Science and Research (IJSR) \\ ISSN (Online): 2319-7064 \\ Index Copernicus Value (2013): 6.14 | Impact Factor (2014): 5.611}

study revealed major errors in word choice $(55 \%)$, followed by mechanics $(20 \%)$, style (16\%) and grammar (9\%).

The same finding was revealed in the study of Lee (2002), who had the strong motivation to conduct an error analysis to examine what kind of errors learners of intermediate to advanced level at a medical college make in writing by reviewing their formal and informal letters. His study revealed that major errors involved were errors in word choice, followed by errors in prepositions and articles.

These findings simply mean that the students have to be encouraged and motivated to read a lot of materials to increase their vocabulary. According to Malicsi (2003), correct use of words in any language task is indispensible so as the idea conveyed is clear and understandable, especially that several words may seem to have similar meanings, but in real sense, they have different meanings.

Errors in spelling (30 or $7.61 \%$ ) also constitute a significant problem in the studentse writings. Based on the written compositions of the students, many of them are confused with the correct spelling of the English words due to the interference of their L1. The L1 and the L2 of the students have different sound systems, making it difficult for them to learn and master the correct spelling of some words in English. Furthermore, these spelling errors are mainly due to phonetics perception and students ${ }^{\text {ee }}$ carelessness. The students spell out words by referring to the sound of the words. They admitted that they do not know how to produce a word correctly for appropriate spelling. Whenever they encounter tough word in the text, they just simply try to get it by heart that occurs incorrect spelling in write up subsequently. Studentse carelessness also causes them to make spelling mistakes. These errors in spelling are evident in the following samples:

\section{Did you loose your cell phone?}

What is wrong with that? Loose this is actually spelling mistake, it should be spelled like this (lose) loose is an adjective which mean not touched and lose is the opposite of find and the pronunciation is loose and not lose.

It can be further gleaned from the table that errors in prepositions $(26$ or $6.60 \%$ ) are considered common linguistic errors committed by the students, indicating the students ${ }^{\text {ee }}$ poor knowledge on the use of prepositions. From the students ${ }^{\text {ee }}$ written compositions, the prepositions were used interchangeably. For the students, prepositions do not affect the meanings of their sentences. Thus, they are not so particular or meticulous on the use of prepositions in their sentences. Carelessness appears to be one of the primary causes of such errors. This linguistic phenomenon is exemplified in the following samples:

He is ill since last week.

He has been working since two hours.

I have not played cricket since a long time.

When reckoning from a particular date we use ,since Examples are since last Friday, since May, since morning, since July 8th. But note that we always use ,for ${ }^{\text {ee }}$ for a period. Examples are: for a week, for a long time, for two hours etc.

So, they must be:

He has been ill since last week.

He has been working for two hours.

I have not played cricket for a long time.

Such findings are confirmed by the result of the study of Lennon (1987) and Lee (2002) which revealed that errors in prepositions are considered second most common errors committed by English language learners.

Prepositions are always followed by nouns (or pronouns) and usually indicate relationships, such as position, place, direction, time, manner, agent, possession and condition, between their objects and other parts of the sentence (Wishon\& Burks, 1980, as cited by Haryanto, 2007). In using a preposition, one has to be aware because there is no certain rule for this. One has to determine which preposition should be used based on its context. Interestingly, the students confessed that they read a lot about preposition from grammar books but they seldom make use of it in practice. This only implies that the students lack drills along the said area of concern. Thus, their language teachers should provide them exercises on the use of preposition to master this said skill.

Obviously, the students used articles incorrectly in their compositions. With 24 (6.09\%) total number of occurrences, errors in articles are also considered common linguistic errors of the students. It can be observed from the students ${ }^{\text {ee }}$ writings that they could hardly identify the differences and meanings embedded on the three articles ( $a$, an, and the). The students are not aware that the articles carry with them corresponding meanings. Hence, they have poor knowledge in article use. They just simply use articles because they feel like using them without considering their effects in the meaning of their sentences. Some others do not even bother to use articles at all. They omit the articles because they are not sure whether they need to use them or not.

To be able to use an article properly, the students have to be sensitive in differentiating the use of definite article, indefinite article and even using no article at all. If they are not able to differentiate them, they will make errors as follows:

We live in village.

She works in pub.

A singular common noun (e.g. boy, girl, tree, country, teacher, village etc.) must have an article. A plural common noun can be used with or without an article.

So they must be:

We live in a village. OR We live in the village. She works in a pub. OR She works in the pub.

Basically, the article " $A$ " is used before noun which is started by consonant and " $A n$ " is used for vowels. But there are some different rules in using " $A$ " and " $A n$ " and very few students know it. According to Huang (2001), even some students do not know that there is a matter of sound in 


\section{International Journal of Science and Research (IJSR) \\ ISSN (Online): 2319-7064}

Index Copernicus Value (2013): 6.14 | Impact Factor (2014): 5.611

using article like "hour" starting by consonant but before "hour" "an" should be placed. For example:

\section{I want a honest friend, whom I can depend on. (an)}

The result corroborates the study of Kim (1998) on the essay writings of 20010 th grade Korean EFL learners. He (1998) identified 2122 errors and classified them in terms of six domains and subdivided them into 22 linguistic categories. His findings revealed that errors in articles were most common (354). This can also be verified in the study of Lee (2002) which revealed that errors in articles were considered third most common grammatical errors committed by English language learners.

Further, the result validates the study of Duskova (1969) who identified a total of 1007 errors from the writings of 50 Czech learners of English and analyzed them in terms of nine categories. The study revealed that errors in articles were the most frequent among the indicated errors of the learners, followed by errors in lexis, while there were only few errors in syntax and word order.

Meanwhile, the least common linguistic errors committed by the students in their written compositions include errors on singular/plural, adjectives, relative clauses, possessive cases of nouns and word order, with 4 (1.01\%) occurrences each.

For the purpose of identifying the types of linguistic errors committed by the students, the errors are summarized in Table 2.

The table shows the summary of linguistic errors in the English writings of the students. It can be deemed from the table that grammatical errors (154 or $39.02 \%$ ) rank first among all the linguistic errors committed by the students, followed by mechanics/substance errors (102 or $25.86 \%$ ), syntactic errors (90 or $22.84 \%$ ). Only few errors were observed along lexical (36 or $9.14 \%$ ) and semantic (12 or 3.05) errors.

Table 2: Summary of errors in the English writings of the students

\begin{tabular}{|c|c|c|c|}
\hline Linguistic Errors & $\begin{array}{c}\text { Count of } \\
\text { error (f) }\end{array}$ & $\begin{array}{c}\text { Percentage } \\
(\mathbf{\%})\end{array}$ & $\begin{array}{c}\text { Hierarchy } \\
(\mathrm{r})\end{array}$ \\
\hline Grammatical Errors & 154 & 39.02 & 1 \\
\hline Mechanics/Substance & 102 & 25.86 & 2 \\
\hline Syntactic Errors & 90 & 22.84 & 3 \\
\hline Lexical Errors & 36 & 9.14 & 4 \\
\hline Semantic Errors & 12 & 3.06 & 5 \\
\hline Total & 197 & 100.00 & \\
\hline
\end{tabular}

All these indicated results imply that the students have difficulties in writing English, particularly on the grammatical, substance or mechanics and syntactic aspects.

The results of this study could help language teachers to assess their own teaching methodologies and their students' ability in writing and to guide them in choosing the strategies and topics that are best suited to their students. More importantly, this study could serve as basis in the development of a coherent program that addresses the students ${ }^{\text {ee }}$ difficulties and needs in writing.
Competency and proficiency in the language is very indispensable nowadays for the world needs globally competitive individuals, who can fluently and can competently use the international language -the English language.

\section{Conclusion}

In the light of the findings, it can be concluded that the common linguistic errors in the English writings of the teacher education students were errors in verb tenses, sentence structure, punctuations, word choice, spelling, prepositions and articles. These errors fall under the grammatical, mechanics/substance and syntactic aspects of writing English. Majority of these errors are caused by the learners ${ }^{\text {ee }}$ poor knowledge of the target language, particularly ignorance of rule restrictions. Others are caused by the learners ${ }^{\text {ee }}$ carelessness, first language transfer or interference and limited vocabulary in the target language.

Analyzing linguistic errors in students ${ }^{\text {ee }}$ English writings is indeed an interesting endeavor in the field of language teaching and learning. Error Analysis (EA) provides a shift or direction toward a more positive treatment on student linguistic errors in their writings. It brings changes in teachers ${ }^{\text {ee }}$ attitudes toward errors, evident in a less obsessive avoidance of errors. It lets language teachers picture out and understand how language learning takes place in the minds of learners. Hence, language teachers are given the opportunity to find ways on how to improve their instruction to address their learners ${ }^{e e}$ difficulties and needs.

\section{Recommendations}

Based on the findings and conclusions, the researcher offers the following recommendations:

The following recommendations are suggested by the researcher based on the findings of the study:

1) A more comprehensive study on the English writings of the students has to be conducted by other research enthusiasts to validate the results of the study.

2) Language teachers have to consider the results and findings of the study in providing opportunities for students to practice and apply language structures in real contexts so as to enhance language skills in the problem areas.

3) Curriculum developers need to revisit the existing language curriculum in the tertiary level to develop a relevant and coherent program to address the foregoing students ${ }^{\text {ee }}$ needs and difficulties.

4) Syllabus designers need to improve their syllabi by incorporating target standards and competencies that may address students ${ }^{\text {ee }}$ linguistic errors in writing.

\section{References}

[1] AbiSamra, N. (2003). An Analysis of Errors in Arabic Speakers' English Writings. Unpublished master"s thesis. American University of Beirut. 
[2] Brown, D. (1994). Principles of Language Learning and Teaching. Prentice Hall, Inc.: United States of America.

[3] Corder, S.P. (1974). The Significance of Learners' Errors. London: Longman.

[4] Corder, S.P. \& Allen, P. (1974). Error Analysis: Language and Language Learning. London: Oxford University Press.

[5] Chomsky, N. (1965). Aspects of the Theory of Syntax. Cambridge, London: MIT Press.

[6] Darus, S. \& Ching, K. H. (2009). Common Errors in Written English Essays of Form One Chinese Students: A Case Study. European Journal of Social Sciences. Vol. 10, 242-253.

[7] Duskova, L. (1969). On Sources of Errors in Foreign Language Learning. International Review of Applied Linguistics, Vol. 7, 11-36.

[8] Gass, S. \&Selinker, L. (2001). Second Language Acquisition: An Introductory Course. Mahwah, NJ: LEA.

[9] Haryanto, T. (2007). Grammatical Error Analysis in Students' Recount Text. Published Master Thesis. Semarang State University, Indonesia.

[10]Huang, S. L. (2001). Error Analysis and Teaching Composition. Unpublished master's thesis. National Tsing Hua University.

[11] Kim, E. J. (1988). A Study of the Errors in the Use of the English Verbs with Special Reference to Tense, Mood, and Voice. Unpublished masteres thesis. Busan National University, Busan, Korea.

[12]Lee, E. (2000). Error Analysis on Medical Students' Writings. Unpublished master"s thesis. Eulji University, School of Medicine.

[13]Lennon, P. (1987). An Analysis of Learners' Errors Made in their English Composition especially in the High School Level. Unpublished master's thesis. Chungbuk National University, Chungju, Korea

[14]Lim, H.P. (1990) An Error Analysis of English Compositions Written by Malaysian-speaking High School Students. Unpublished master's thesis. University of California.

[15]Malicsi, J. (2003). Grammar and Composition. University of the Philippines: Diliman, Quezon City.

[16]Myles, J. (2003). Second Language Writing and Research: The Writing Process and Error Analysis in Students Texts. Queen's University.

[17]Richards, J.C. (ed.). (1992). Error Analysis: Perspectives on Second Language Acquisition. Longman Group Limited.

[18] Richards, J. C., Platt, J. \& Platt, H. (2002). Language Teaching and Applied Linguistics. Essex: Longman Group UK Limited.

[19] Sukasame, N. Kantho, S., \&Narrot, P. (2014). A Study of Errors in Learning English Grammatical Structures on Tenses of MatthayomSuksa 4 Students of The Demonstration School, KhonKaen University. Procedia - Social and Behavioral Sciences. Vol. 116, 1934-1939. 